\title{
Clomiphene citrate versus letrozole for ovulation induction in anovulatory infertility: a prospective study
}

\author{
Monica Soni, Gajendra Kumar Kalal, Arti Meena, Anita Sharma*
}

Department of Obstetrics and Gynecology, P. B. M. Hospital, S. P. Medical College Bikaner, Rajasthan, India

Received: 23 February 2020

Accepted: 27 March 2020

*Correspondence:

Dr. Anita Sharma,

E-mail:dr.gkkalal@gmail.com

Copyright: (C) the author(s), publisher and licensee Medip Academy. This is an open-access article distributed under the terms of the Creative Commons Attribution Non-Commercial License, which permits unrestricted non-commercial use, distribution, and reproduction in any medium, provided the original work is properly cited.

\begin{abstract}
Background: The objective of this study was to compare clomiphene citrate with letrozole for ovulation induction in anovulatory infertile women.

Methods: This study was conducted in the infertility clinic and department of obstetrics and gynecology, S.P. Medical College and Associated P. B. M. Hospital, Bikaner, Rajasthan, from $1^{\text {st }}$ August 2018 to $31^{\text {st }}$ July 2019. The study group comprised of infertile females attending infertility clinic or gynae outdoor in department of obstetrics and gynecology, S. P. Medical College Bikaner for infertility. 100 women with anovulatory infertility were enrolled in the study after fulfilling the inclusion and exclusion criteria. Proper counseling was done and written informed consent taken.

Results: Ovulation rate was statistically significantly greater in letrozole group. Monofollicular development was statistically significant greater in let group (CC 18\%, Let 66\%). The endometrial thickness on the day of $\mathrm{BhCG}$ administration in CC group was $7.40 \pm 1.08 \mathrm{~mm}$ and in let group was $8.20 \pm 0.82 \mathrm{~mm}$. Letrozole treated cases had better trilaminar pattern of endometrium as compared to clomiphene. The pregnancy rate was higher in letrozole group.

Conclusions: As compare to clomiphene, letrozole is associated with higher pregnancy rate and ovulation rates among infertile women with anovulation.
\end{abstract}

Keywords: Anovulation, Clomiphene, Infertility, Letrozole

\section{INTRODUCTION}

Ovulatory dysfunction is a common problem and is responsible for about $40 \%$ cases of female infertility. ${ }^{1}$ It manifests as amenorrhea, oligomenorrhea or polymenorrhea with painless periods. ${ }^{1}$ Recent years have seen a significant rise in number of women presenting with chronic anovulation due to ovulatory dysfunction. PCOS is the most common cause of infertility due to chronic anovulation. ${ }^{2}$ Using the Rotterdam criteria, a clinical diagnosis of PCOS is easily reached and most often treatment can be initiated following a few basic investigations and exclusion of other female and male factors responsible for infertility. ${ }^{3}$ Hypothyroidism is another common cause of anovulation and infertility.,5
Other causes of anovulation include hyperprolactinemia, pituitary causes, hypothalamic causes, obesity, premature ovarian failure, extreme exercises etc. ${ }^{6}$ A large subset of patients with amenorrhea or oligomenorrhea and chronic anovulation seek care because they are unable to conceive. The goal of ovulation induction refers to the therapeutic restoration of the release of one egg per cycle in a woman who either has not been ovulating regularly or has not been ovulating at all. Various drugs are used for induction of ovulation e.g. clomiphene citrate (CC), letrozole (let), human menopausal gonadotropin (HMG), follicle stimulating hormone (FSH), gonadotropin releasing hormone (GnRH) agonists etc. ${ }^{7}$ Gonadotropins are more effective than $\mathrm{CC}$ but are expensive and associated with higher risk of ovarian hyperstimulation 
syndrome and multiple gestations. In view of the cost and possible complications of gonadotropins, fertility care prefers using easy to use, less expensive and effective drugs like clomiphene and letrozole. ${ }^{8}$

Clomiphene citrate (CC) is a long-standing, standard drug for ovulation induction and is still considered as first-line option for ovulation induction. It is orally administered, has fewer side effects, easily available and inexpensive. However, treatment with clomiphene citrate is associated with discrepancy in ovulation and pregnancy rates (60$85 \% ; 10-20 \%)$. Miscarriage rate is higher than general population and $20-25 \%$ of PCOS women are resistant to clomiphene.

Anti-estrogenic effect of clomiphene citrate leads to prolonged depletion of estrogens receptors, adversely affecting endometrial growth as well as quantity and quality of cervical mucus., ${ }^{9,10}$ Clomiphene citrate resistance together with side effects like multi-follicular development, poor endometrial growth and cyst formation are areas of concern. The desire for an effective alternative persists.

Letrozole, an aromatase inhibitor, was introduced into infertility practice in the year 2000 and is regarded as a good treatment option for ovulation induction, particularly in women with clomiphene resistance. Letrozole acts by inhibiting the enzyme aromatase which converts androgen into estrogen. ${ }^{11}$ It has found acceptance in various clinical situations and the indications for use have expanded. In contrast to clomiphene, letrozole at the customary dose of $2.5-5 \mathrm{mg}$ elicits a mono follicular response and does not adversely affect either the endometrium or the cervical mucus due to absence of its effect on peripheral estrogen receptor. This study was conducted to compare clomiphene citrate with letrozole for ovulation induction in anovulatory infertility woman.

\section{METHODS}

This study was conducted in the infertility clinic and department of obstetrics and gynecology, S. P. Medical College and associated P. B. M. Hospital, Bikaner, Rajasthan, from $1^{\text {st }}$ August 2018 to $31^{\text {st }}$ July 2019. Total 100 women with anovulatory infertility were enrolled in the study after fulfilling the inclusion and exclusion criteria. Proper counseling was done and written informed consent taken.

\section{Inclusion criteria}

- Women in age group of 18-45 years who haven't conceived after one year of regular, unprotected intercourse (primary infertility) or who have conceived earlier and had successful or failed pregnancy but now unable to conceive (secondary infertility) having features of anovulation were included in the study.

\section{Exclusion criteria}

- Patients with male factor infertility, ovarian cysts, unilateral or bilateral tubal block, liver disease and dysfunction, abnormal uterine bleeding, uncontrolled thyroid dysfunction, premature ovarian failure

- Patients with medical or surgical disorders which may affect course of study, drugs that may interfere with result, known sensitivity to clomiphene and letrozole and contraindications to clomiphene and letrozole were not included in the study.

After baseline ultrasound scan on day 2, cases were randomized into two groups, to receive either $50 \mathrm{mg}$ of clomiphene citrate (Group A) or $2.5 \mathrm{mg}$ of letrozole (Group B) daily for 5 days starting from day 2 or 3 of menstrual cycle. Group A received clomiphene citrate and Group B received letrozole. Follicular monitoring was done by serial ultrasound scan from day 8 of menstrual cycle. Growth of follicle, endometrial thickness and free fluid in pouch of douglas was monitored. When a follicle attained a size of approximately $18 \mathrm{~mm}$ diameter, a single injection of hCG 5000 IU was given if endometrial thickness was adequate. Endometrial thickness on day of hCG administration was recorded. Timed intercourse was advised to the patient for 3 days after hCG injection. Repeat scan was done 48 hours after hCG injection for all patients to confirm rupture of follicle and presence of free fluid in pouch of Douglas. If not ruptured, a final scan was done after 72 hours to check for luteinized unruptured follicle or delayed rupture. Ovulation was confirmed by sonographic finding of ruptured follicle and free fluid in pouch of Douglas. Urine beta human chorionic gonadotropin (BhCG) test was done after missed periods. Women who failed to ovulate with $50 \mathrm{mg}$ clomiphene citrate or $2.5 \mathrm{mg}$ letrozole or have inadequate endometrial thickness was noted.

\section{RESULTS}

Total 100 cases with anovulatory infertility were included in the study (50 cases in the CC Group A and 50 cases in Let Group B). Age, duration of infertility, BMI, were similar in both groups (Table 1). Ovulation rates were found to be statistically higher in Group B (CC62\%, Let $82 \%$ ) (Table 1). Mono follicular development was statistically significantly higher in Group B (CC 18\%, Let $66 \%$ ) (Table 2). There was no statistically significant difference between the groups in day of ovulation (Table 2).

Endometrial thickness on the day of BhCG administration was found statistically significantly greater in Group B

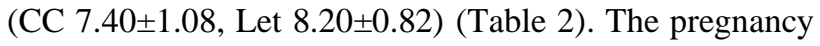
rate was higher in letrozole group as compared to clomiphene (10\% versus $24 \%$ ) (Table 2). Minor side effects were observed in both groups with insignificant $\mathrm{p}$ value (Table 3 ). 
Table 1: Case characteristic of Group A and Group B.

\begin{tabular}{|llll|}
\hline & Group A (Clomiphene citrate) & Group B (Letrozole) & p value \\
\hline Age (in years) & $25.06 \pm 4.07$ & $25.44 \pm 4.60$ & NS \\
\hline BMI $\left(\mathrm{kg} / \mathrm{m}^{2}\right)$ & $23.2150 \pm 3.73139$ & $23.9057 \pm 3.428$ & NS \\
\hline Mean duration of infertility (years) & $5.01 \pm 2.9803$ & $4.85 \pm 2.4913$ & NS \\
\hline Type of infertility (primary) & $92 \%$ & $84 \%$ & NS \\
\hline
\end{tabular}

NS: Not significant.

Table 2: Outcome of ovarian stimulation.

\begin{tabular}{|llll|}
\hline Outcomes & Group A (Clomiphene citrate) & Group B (Letrozole) & p value \\
\hline Ovulation rate & $62 \%$ & $82 \%$ & 0.045 \\
\hline Mono follicular development & $18 \%$ & $66 \%$ & 0.0001 \\
\hline $\begin{array}{l}\text { Endometrial thickness on the of hCG } \\
\text { administration (mm) }\end{array}$ & $7.40 \pm 1.08$ & $8.20 \pm 0.82$ & 0.0001 \\
\hline Day of ovulation & $14.19 \pm 1.40$ & $13.73 \pm 0.74$ & $\mathrm{NS}$ \\
\hline Endometrial pattern (Trilaminar) & $56 \%$ & $84 \%$ & 0.005 \\
\hline Conception rate & $10 \%$ & $24 \%$ & $\mathrm{NS}$ \\
\hline
\end{tabular}

Table 3: Distribution of cases according to side effects of the drug.

\begin{tabular}{|c|c|c|c|c|c|}
\hline \multirow{2}{*}{ Side effect } & \multicolumn{2}{|c|}{ Group A (Clomiphene citrate) } & \multicolumn{2}{|c|}{ Group B (Letrozole) } & \multirow{2}{*}{ p value } \\
\hline & No. & Percentage & No. & Percentage & \\
\hline Mood swing & 5 & $10 \%$ & 4 & $8 \%$ & $0.977(\mathrm{NS})$ \\
\hline Abdominal discomfort & 4 & $8 \%$ & 3 & $6 \%$ & $0.980(\mathrm{NS})$ \\
\hline Headache & 4 & $8 \%$ & 5 & $10 \%$ & 0.977 (NS) \\
\hline Nausea/vomiting & 3 & $6 \%$ & 2 & $4 \%$ & $0.983(\mathrm{NS})$ \\
\hline Dizziness & 2 & $4 \%$ & 3 & $6 \%$ & $0.983(\mathrm{NS})$ \\
\hline
\end{tabular}

NS: Not significant.

\section{DISCUSSION}

Infertility is becoming a major health concern worldwide with increased public awareness as well as advancement in infertility management. Infertility has been attributed to various factors, amongst which anovulation is the cause of about $40 \%$ of all female infertility. Clomiphene citrate has been used as a first line agent for ovulation induction for many years. However, clomiphene citrate reduces uterine receptivity and its anti-estrogenic effect reduces the chances of conception in spite of successful ovulation. It is associated with endometrial thinning in $15-50 \%$ of cases, probably due to estrogen receptor depletion. Letrozole, which is an aromatase inhibitor, has been explored as a good alternative by many researchers but the evidence about its efficacy as compared to clomiphene is conflicting.

The two Groups A and B were comparable for study with regard to age, residence, literacy, duration and type of infertility and BMI of cases. Rate of ovulation was higher in Group B than Group A in this study with statistically significant $\mathrm{p}$ value. Higher ovulation rate was also noted by Atay $\mathrm{V}$ et al and Begum et al. ${ }^{12,13}$ The difference in mechanism of action of both the drugs explains higher ovulation rate with letrozole as compared to clomiphene citrate. Letrozole blocks conversion of androgens to estrogens and this releases pituitary from negative feedback of estrogen and lead to increased FSH levels. Also, there is an added positive effect is increased follicular sensitivity to FSH through amplification of FSH receptor gene expression.

In this study, the mean day of ovulation in Group A and in Group B was $14.19 \pm 1.40$ and $13.73 \pm 0.74$ respectively, with $\mathrm{p}$ value of 0.076 , which is insignificant. In the study conducted by Kar $\mathrm{S}$ et al, mean day of ovulation was 14.2 \pm 3.41 with clomiphene citrate and $13.13 \pm 2.99$ with letrozole. ${ }^{14}$ Mobusher I et al, observed no statistically significant difference between the two groups in days to ovulation. ${ }^{15}$ Mean day of ovulation in this study correlates well with physiological day of ovulation.

Multi follicular development was statistically significantly higher in cases treated with clomiphene citrate whereas mono follicular development was greater in cases treated with letrozole $(66 \%)$. This is expected and corroborated by number of studies. Airao BB et al, concluded that letrozole is associated with better mono follicular development as compared to clomiphene (78.32\% versus 55.76\%). ${ }^{16}$ Mobusher I et al, concluded that mono follicular growth is significantly higher in patients treated with letrozole $(79.49 \%)$. There was a 
significantly greater chance of singleton pregnancy with letrozole than with clomiphene. Multi follicular development with clomiphene citrate may lead to complications like ovarian hyperstimulation syndrome and multiple pregnancies. Another important observation was that in spite of multi follicular development with clomiphene, the ovulation and pregnancy rate was significantly lower than letrozole. This could be due to poor follicle quality, unruptured luteinized follicle and anti-estrogenic effects of clomiphene citrate on endometrium.

In this study, the mean endometrial thickness on day of BhCG administration in Group A was 7.044 $\pm 1.052 \mathrm{~mm}$ and in Group B was $8.142 \pm 0.814 \mathrm{~mm}$ with $\mathrm{p}$ value of 0.0001 , which was statistically highly significant. The mean endometrial thickness was significantly higher in letrozole group (Group B). Atay V et al, in their study found greater endometrial thickness with letrozole. Mohamed FM et al, also reported letrozole to have greater endometrium thickness. ${ }^{17}$ It is well known that the endometrium is the most important target of the antiestrogenic effect of clomiphene citrate. On the contrary, letrozole avoids endometrial side effects. Successful implantation requires a receptive endometrium with synchronous development of glands and stroma. Few studies have shown no significant difference between the two groups with regards to effect on endometrium like Kar $\mathrm{S}$ et al, found no significant difference in their study with regards to effect on the endometrium. $^{12}$

In this study, letrozole treated cases were found to have more number of cases with trilaminar endometrial pattern. In Group A, 56\% cases had trilaminar pattern while in Group B, 84\% cases had trilaminar pattern of endometrium. Fisher et al, demonstrated that letrozole treated cases had more number of cases with trilaminar pattern of endometrium as compared to clomiphene. The investigators concluded that letrozole was associated with better receptive uterine environment for implantation. Similar results were found in this study.

The number of conceptions was high in letrozole group $(24 \%)$ in this study. Airao BB, Mobusher I, Kar S and Atay $\mathrm{V}$ et al, have also reported higher chances of conception with letrozole. Clomiphene has peripheral antiestrogenic action at the level of the endometrium and cervical mucus and found to have low ovulation rates thus explaining lower conception rates as compared to letrozole. Thinning of endometrium, altered echo pattern, prolonged depletion of estrogen receptors and hostile cervical mucus negatively influence conception rates with clomiphene citrate. Henceforth, letrozole has higher pregnancy rates as compared to clomiphene. No serious adverse effects were noted with either drug. However, mood swings, abdominal discomfort, headache, nausea, vomiting and dizziness were noted in some cases. 5 cases in Group A and 4 cases in Group B reported mood swings. 4 cases in Group A and 3 cases in Group B reported abdominal discomfort. 4 cases in Group A and 5 cases in Group B reported headache during the course of treatment. Legro RS at el reported a significant higher incidence of hot flushes with clomiphene and fatigue and dizziness with letrozole. They also reported their serious adverse effects related to ovarian cyst formation. However, study did not observe any major adverse effects with either drug. This could be related to use of low dose clomiphene and letrozole and administration for a single cycle. However, strict monitoring is advised with use of higher dosage of drugs and multiple cycle administration.

\section{CONCLUSION}

The results of this randomized trial suggest that letrozole is a good alternative in term of ovulation and conception rates with significantly better endometrial thickness and mono follicular development. However, there is need for larger randomized trials to generate robust data in order to establish the true potential of letrozole.

\section{Funding: No funding sources \\ Conflict of interest: None declared}

Ethical approval: The study was approved by the Institutional Ethics Committee

\section{REFERENCES}

1. Baerwald AR, Adams GP, Pierson RA. A new model for ovarian follicular development during the human menstrual cycle". Fertil. Steril. 2003;80(1):116-22.

2. Hoffman BL, Schorge JO, Bradshaw KD (eds), Williams Gynecology, $3^{\text {rd }}$ edn, Mcgraw Hill Education, New York, USA; 2016:334-368.

3. Stein IF, Leventhal ML. Amenorrhea associated with polycystic ovaries. Am J Obstet Gynecol. 1935;29:181-91.

4. Setji T, Brown A. Polycystic ovary syndrome: diagnosis and treatment. Am J Med. 2007;120:128.

5. Mohammad MB, Seghinsara AM. Polycystic ovary syndrome (PCOS), diagnostic criteria and AMH. Asian Pac J Cancer Prev. 2017;18(1):17-21.

6. Legro RS. Evaluation and treatment of polycystic ovary syndrome. InEndotext; 2017. MDText. com, Inc. 2017:11.

7. Molitch ME, Reichlin S. Hyperprolactinemic disorders. Disease-a-Month. 1982;28(9):6-58.

8. Hoffman BL, Schorge JO, Bradshaw KD (eds), Williams Gynecology, $3^{\text {rd }}$ edn, Mcgraw Hill Education, New York, USA; 2016:334-368.

9. Topipat C, Choktanasiri W, Jultanmas R, Weerakiet S, Wongkularb A, Rojanasakul A. A comparison of the effects of clomiphene citrate and the aromatase inhibitor letrozole on superovulation in Asian women with normal ovulatory cycles. Gynecol Endocrinol. 2008;24(3):145-50.

10. Keren JF, Liu Jh, Phillipou G, Yen S. Evidence for a hypothalamic site of action of clomiphene citrate in women. J Clin Endocrinol Metab. 1985;61:265-58. 
11. Lonning $\mathrm{P}$, Pfister C, Martoni A, Zamagni C. Pharmacokinetics of third-generation aromatase inhibitors. Semin Oncol. 2003;30 (Suppl 14):23-32.

12. Kauffman RP, Baker VM, Dimarino P, Gimpel T, Castracane VD. Polycystic ovarian syndrome and insulin resistance in white and Mexican American women: a comparison of two distinct populations. Am J Obstet Gynecol. 2002;187(5):1362-9.

13. Begum MR, Ferdous J, Begum A, Quadir E. Comparison of efficacy of aromatase inhibitor and clomiphene citrate in induction of ovulation in polycystic ovarian syndrome. Fertil Steril. 2009;92:853-7.

14. Atay V, Cam C, Muhcu M, Cam M, Karateke A. Comparison of Letrozole and Clomiphene citrate in women with polycystic ovaries undergoing ovarian stimulation. J Int Med Res. 2006;34:73-6.

15. Casper RF. Letrozole versus clomiphene citrate: which is better for ovulation induction? Fertil Steril. 2009;92:858-9.
16. Airao BB, Vasava V, Patel D. Comparison of the efficacy of letrozole and clomiphene citrate for ovulation induction in infertile women with polycystic ovary syndrome. Inter J Current Res. 2019;11:4346-9.

17. Mitwally FM, Casper RF. Use of letrozole for ovulation in patients with an inadequate response to CC. Fertil Steril. 2001;75(2):305-9.

Cite this article as: Soni M, Kalal GK, Meena A, Sharma A. Clomiphene citrate versus letrozole for ovulation induction in anovulatory infertility: a prospective study. Int J Reprod Contracept Obstet Gynecol 2020;9:2004-8. 